DOI: 10.14451/1.178.13

\title{
ОЦЕНКА МЕТОДОВ УПРАВЛЕНИЯ СТОИМОСТЬЮ СТРОИТЕЛЬНЫХ ПРОЕКТОВ
}

\author{
(c) 2019 Брыжатый Даниил Ринатович
}

бакалавр, студент магистратуры кафедры строительных материалов и технологий строительства

Сибирский федеральный университет, Россия, Красноярск

E-mail: bruzhatui@yandex.ru

(c) 2019 Пронин Павел Викторович

студент кафедры радиосистем и комплексов управления

Сибирский федеральный университет, Россия, Красноярск

E-mail: g.f.05@inbox.ru

(c) 2019 Можора Мария Алексеевна

студентка кафедры психологии и консультирования

Сибирский федеральный университет, Россия, Красноярск

E-mail:m.mozhora@yandex.ru

(c) 2019 Зайцева Анжелика Александровна

студент кафедры промышленного и гражданского строительства

Сибирский федеральный университет, Россия, Красноярск

E-mail: anje.zaitseva@yandex.ru

(c) 2019 Родионенко Евгения Викторовна

студент кафедры промышленного и гражданского строительства

Сибирский федеральный университет, Россия, Красноярск

E-mail: rodionaaaa@mail.ru

(c) 2019 Короткова Светлана Андреевна

студент кафедры экспертизы и управления недвижимостью

Сибирский федеральный университет, Россия, Красноярск

E-mail: svetlanna4443@gmail.com

В наше время в строительной отрасли происходит ряд изменений, связанных с инновационными методами реализации проектов. Управление стоимостью проекта - одна из основных функций управления проектом. В данной статье представлен анализ инновационных методов управления стоимостью строительных проектов, основанных на цифровых технологиях. Представлены преимущества и недостатки каждого из методов, проанализированы перспективы развития цифровых технологий в строительных проектах.

Ключевые слова: строительство, строительный проект, стоимость, управление, цифровые технологии, ВІМ, бюджет.

На основании международных подходов стоимостью проекта считается стоимость необходимых затрат для его реализации. В управление стоимостью проекта входит несколько процессов: создание плана, анализ потребностей бюджета, подготовка бюджета, привлечение и осуществление инвестирования, управление и контроль стоимости, обеспечение исполнения проекта в рамках установленного бюджета [1].

Для начала рассмотрим этапы управления стоимостью проекта (далее УСП). Начальным этапом управления является разработка плана, где требования организации представлены как функциональные или ограничивающие потребности к управляемому проекту строительства, это могут быть экономические, технические, природные, социальные и другие требования.

Для сравнения возможных вариантов развития проекта применяются технико-экономические показатели. Для улучшения характеристик объекта строительства с точки зрения инвестора рассматриваются разные этапы строительного 
цикла. В таком случае показатели прибыли и затрат оценивают используя экономико-математические системы.

Следующим шагом после планирования является выполнение. До начала этого этапа необходимо сформировать коллектив и выбрать руководителя проекта. В основном, человек, руководящий проектом возведения комплекса зданий является техническим заказчиком. Вместе с тем, при строительстве объекта «под ключ» по подрядному договору, руководителем проекта назначается уполномоченный представитель от генерального подрядчика, который несет ответственность за УСП.

Третьим этапом УСП является анализ результата выполнения. Для этого традиционно используют бухгалтерскую систему учета, с использованием различных систем, в которые вносят суммы накладных расходов и ранжируют в соответствии с прямыми затратами во время строительства. В некоторых случаях в УСП используют нетрадиционный подсчет расходов обуславливаемых видом деятельности в строительстве. При использовании данного метода, помимо прямых расходов еще учитывается и большая часть непрямых (косвенных) трат, для обеспечения определенных видов работ и процессов. В таком случае вводится понятие «центр затрат», в которое входят расходы от производственных и вспомогательных подразделений подрядчика, а также организаций работающих по субподрядному договору [1].

Для окончания управления циклом следует произвести анализ результата произведенных расходов. Для оценки сначала сравнивают норму выработки фирмы за прошлые периоды, а потом - запланированные показатели, полученные на основании статистики. Параметром оценки результата реализуемого объекта строительства является показатель экономической эффективности (чистая дисконтированная стоимость и др.), но вычисленный не по запланированным, а по текущим данным.

Далее рассмотрим современные методы снижения стоимости строительных проектов. Сущность инновационных способов заключается в применении цифровых технологий, именно они сыграли большую роль для скорого ввода инноваций во все сферы человеческой деятельности, за счет обеспечения повышенной продуктивности, рентабельности, производства труда. В то же время, цифровые технологии мало затронули строительную сферу, в которой за полвека не было серьезных изменений [2].

Первопричина неторопливого внедрения инновационных процессов в строительную отрасль обусловлена широкомасштабностью и децентралированным характером. Как посчитано WEF [3], строительная сфера формирует около 6\% ВВП во всем мире и набирает обороты. Считается, что к 2025 году прибыль строительства достигнет \$15 триллионов, это в 1.5 раза больше сегодняшнего уровня. Строительство является крупным потребителем ресурсов, расходуя каждый год примерно 50\% доли от всей выпускаемой стали и более 3 млрд. тонн сырья. Потому небольшое нововведение, повышающее эффективность труда в строительстве может сократить расходы на $\$ 100$ миллиардов в год во всем мире.

Главными причинами, которые мешают развитию инноваций в строительном бизнесе, являются:

- сложная система организации и регулирования строительного производства;

- несостоятельность процессов управления строительным производством, отсутствие должного внимания к его тщательной проработке;

- отсутствие возможности управления экономическим эффектом от проектов;

- отсутствие процессов передачи информации от проекта к проекту;

- неразвитость партнерских отношений между вовлеченными соучастниками строительства;

- устаревшие традиции корпоративной культуры, которые не позволяют вовлекать образованных, талантливых, инициативных сотрудников, создавать интеллектуальный капитал, который является главной конкурентной характеристикой.

Большая часть крупных строительных компаний сталкивается с проблемой уменьшения дохода за счет превышения бюджета строительного проекта до 30-50\% [4]. По мнению 70\% всех компаний причиной этого является сложность планирования сроков проекта, а 50\% считают, что всему виной неточные прогнозные подсчеты затрат. Оказывается, что около 15\% материалов, поставленных на стройплощадку, никак не применяются.

Крупные зарубежные компании решают данные проблемы путем применения цифро- 
вых технологий, в которых интегрируются все процессы построения строительного бизнеса. За счет оптимизации сокращаются сроки строительства на 30\%, а себестоимость на $15 \%$.

На сегодняшний день активно развивается отрасль компьютерных технологий для управления строительными проектами. Например, большую популярность набирает BIM (Building Information Modelling) в качестве инструмента управления. К сожалению, на данный момент в таких системах нет возможности регулировать стоимостью проекта.

Главным параметром в УСП является скорость принятия продуманных решений, которые связанны с разными воздействиями на процесс, с точки зрения управления, а так же возможность своевременно и точно спрогнозировать стоимость проекта на любой момент времени. То есть, на скорость принятия какого-либо решения, от которого зависит конечная стоимость проекта, влияет быстрота сбора качественной и достоверной информации. В наше время, она является самым значимым ресурсом, который должен соответствовать высоким требованиям, а грамотно организованная система работы с информационным трафиком обеспечивает компетентность в управлении. От эффективной обработки информации зависит конкурентное преимущество одной строительной организации от другой, а так же создание адекватных отношений между вовлеченными в строительство сторонами.

Исполнение всех требований к информации, без которой невозможно дальнейшее УСП, выполняется в случае наличия единого информационного пространства и общих принципов организации системы информационного обеспечения. Сравним некоторые из способов.

\section{1. Разработка единой информационной си- стемы (ЕИС).}

ЕИС - совокупность методов взаимодействия с информацией, которая указывает о состоянии многих сфер хозяйственных дел компании в единой информационной базе данных с наличием в ней всей отчетности.

Она создается для контроля всех хозяйственных процессов, которые осуществляются всеми подразделениям компании, основа которых - единый план счетов, справочников (НСИ) и аналитических статей. Структура ЕИС должна состоять из иерархической сети, на вершине которой должна стоять центральная система, а под ней второстепенные системы подразделений, находящиеся в той же конфигурации программы. В отдельности любое подразделение может изменять свой массив данных. Сотрудникам чужих разделов недоступна информация смежных подразделений и главной системы. Центр обладает доступом к любым сведениям подчиненных разветвлений и обеспечивает единство данных в системе.

Для централизации действий системы бухгалтерские и налоговые учеты надстраиваются подчиненными системами производственного и управленческого учета, производственного и финансового планирования, бюджетирования и др. Организация структуры системы выстраивается так, чтобы применялась одна информация для различных задач.

Изменение недостатков раздельного информационного обеспечения в преимущества единой автоматизированной системы сведены в таблице 1.

Исходя из этого, работа единой автоматизированной информационной системы обеспечивает контроль над положением текущего бизнеса и улучшение показателей управленческой эффективности.

На данный момент предложения программ в сфере производства ЕИС не так велико из-за сложности задач, которые подставлены перед ними. Причины ограничения спроса на ЕИС таковы:

Разработчики предлагают типовую или адаптированную к специфике конкретной компании программу, в то время когда компаниям нужны методы и основы для организации единой системы. Внедрение и долгий опыт пользования позволит выделить определенный ряд требований и ожиданий от программы.

Предлагаемые программы являются интегрированными комплексами со специальными инструментами, что в свою очередь создает, непреодолимые для большинства организаций проблемы тем, что требуют:

- крупные временные и бюджетные расходы для перехода с одних методов учета на другие, так же сюда входит долгое обучение работников использованию программ;

- программный комплекс не ориентирован на закрытие всех потребностей пользователя, ему приходится самому подгонять свои навыки под обеспечение программы. 
Таблиц̧а 1.

\begin{tabular}{|c|c|c|}
\hline № & $\begin{array}{c}\text { Недостатки информационного обеспечения, } \\
\text { состоящего из отдельных систем }\end{array}$ & $\begin{array}{c}\text { Преимущества единой автоматизированной } \\
\text { информационной системы }\end{array}$ \\
\hline 1 & $\begin{array}{l}\text { Постоянное внесение одной информации в раз- } \\
\text { личные системы. Могут возникнуть несоответ- } \\
\text { ствия данных в виду ошибки при переносе. Из-за } \\
\text { коллективной работы появляется переизбыток } \\
\text { информацией т.к. работа производится в разных } \\
\text { документах }\end{array}$ & $\begin{array}{l}\text { Единоразовое внесение информации исходной } \\
\text { информации и дальнейшее ее использование, } \\
\text { корректировка. Одно изменение отражается во } \\
\text { всех системах, документах. Оптимальное коли- } \\
\text { чесво информации }\end{array}$ \\
\hline 2 & $\begin{array}{l}\text { Искажение информации во время переноса с } \\
\text { бумажных носителей. Так же большое исполь- } \\
\text { зование бумаги может привести к потере самих } \\
\text { данных }\end{array}$ & $\begin{array}{l}\text { Возможность организации бездокументного сбо- } \\
\text { ра и передачи первичной информации (сканиро- } \\
\text { вание документов и т.п.). Минимизация затрат, } \\
\text { связанных с копированием, хранением, повтор- } \\
\text { ным изготовлением документов. }\end{array}$ \\
\hline 3 & $\begin{array}{l}\text { Несопоставимость и неаналитичность информа- } \\
\text { ции из-за отсутствия универсальных регистров, } \\
\text { единых справочников и методик формирования } \\
\text { и обработки информации в разных системах. } \\
\text { Большие затраты времени на сбор, поиск, обра- } \\
\text { ботку информации и получение результирующих } \\
\text { показателей и отчетов. }\end{array}$ & $\begin{array}{l}\text { Унифицированный способ формирования и } \\
\text { обобщения информации: сбор информации } \\
\text { на счетах, которые являются универсальными } \\
\text { регистрами; наличие единых справочников и } \\
\text { методов структуризации и обработки информа- } \\
\text { ции, составления отчетности. }\end{array}$ \\
\hline 4 & $\begin{array}{l}\text { Отсутствие возможности получения аналити- } \\
\text { ческой информации в необходимом разрезе, с } \\
\text { необходимой степенью глубины или обобщения, } \\
\text { на любую дату или за любой период времени. }\end{array}$ & $\begin{array}{l}\text { Наличие возможности получения аналитической } \\
\text { информации в любом разрезе, с заданной степе- } \\
\text { нью глубины или обобщения, за любой период } \\
\text { времени, в течение которого накапливаются } \\
\text { учетные данные. Снижение затрат на анализ } \\
\text { информации }\end{array}$ \\
\hline 5 & $\begin{array}{l}\text { Высокие затраты на поддержание каждой из ав- } \\
\text { томатизированных систем в рабочем состоянии } \\
\text { и обучение персонала работе с каждой из них. }\end{array}$ & $\begin{array}{l}\text { Минимизация затрат на информационное обе- } \\
\text { спечение процесса управления. Быстродействие, } \\
\text { понятность и удобство интерфейса программно- } \\
\text { го комплекса. }\end{array}$ \\
\hline 6 & $\begin{array}{l}\text { Снижение эффективности процесса управления } \\
\text { из-за неадекватного и несвоевременного реаги- } \\
\text { рования на события хозяйственной деятельности } \\
\text { в связи с запаздыванием }\end{array}$ & $\begin{array}{l}\text { Оптимизация процесса управления: сокраще- } \\
\text { ние времени на подготовку управленческих } \\
\text { документов и отчетности, что дает возможность } \\
\text { оперативного реагирования на события хозяй- } \\
\text { ственной деятельности }\end{array}$ \\
\hline
\end{tabular}

2. Использование бюджетного управления в системе производственного планирования и бухгалтерского учета.

Результативность проекта во время его срока исполнения должна обеспечиваться в системе на основании как минимум трех форм: бюджета доходов и расходов (БДР), бюджета движения денежных средств (БДДС), балансового листа (БЛ) и др. В таком случае базой данных для управления бюджетом строительства выступает система производственного планирования. При расчете БДР финансовые итоги долгосрочного проектирования должны выполняться в соответствии с нормами ПБУ 2/2008 «Учет договоров строительного подряда». Для этого нужна специализированная подсистема и ее дальнейшая связь с системой бухгалтерского учета.

Создание в системе БДР, БДДС, БЛ с аналитическими показателями результативности текущего проекта, обеспечивает строительные компании возможностью создания финансово- экономической модели с целью:

- создания нескольких вариантов разработки бизнес-стратегий;

- контроля рисков при проектировании масштабных и долгосрочных проектов;

- прогнозирования возможных показателей финансово-экономического результата строительства и компании в целом;

- совершенствования бизнес-процессов;

- увеличения масштаба бизнеса и т.п.

Оперативная версия предназначена для обработки оперативных документов планирования проекта, которые служат основанием для выполнения решений, согласованных управленческим аппаратом компании. Предусмотрено, что объем данных документов возможно перенести в систему для моделирования и дальнейшей работы с определенными сценариями действий.

После моделирования ситуаций и принятия каких-либо корректировок, изменения перено- 
сятся в другие документы оперативной рабочей версии для принятия этих решений в реальном бизнес-процессе.

Любая информация из операционной структуры планирования может храниться в базе данных и после решения управляющего комитета о принятии бюджета. Это позволит в дальнейшем сделать сравнение всех операционных данных анализа между собой.

\section{3. Взаимодействие с внешними ВIM-систе-} мами.

Данный метод дает возможность создания структурированной информации (состав конструктивных элементов, объем трудозатрат, количество материала и другие параметры проекта), визуальное представление плана и достоверность произведенных работ. Так же позволяет производить коллективную работу над проектом с участием всех сторон строительства с применением внешних информационных моделей типа ВIM-систем. В этом заключается особое отличие данного способа УСП от других.

Данная технология основана на процессе создания общего доступа к информационной модели для всех участников проекта, представляющая собой всю информацию по проекту. ВІМ-процесс позволяет работать с такими функциями как сбор, накопление и комплексная обработка архитектурной, конструкторской, инженерной, технологической, экономической и какой-либо другой информации во время ее использования в едином информационном пространстве.

Для планирования, организации, координации и контроля закупки требуемых материалов, выполнения проектных и строительно-монтажных работ, логистики, передачи в эксплуатацию, требуется вся информация по проекту. При наличии необходимых данных об объекте, появляется возможность быстро принимать грамотные управленческие решения на протяжении всех этапов строительства, повышая продуктивность реализации проекта.

На данный момент зарубежными компаниями установлено, что применение ВIM позволило уменьшить количество возможных ошибок на 30\%, на 100\% удалось выявить все пространственные погрешности в конструкциях, ускорить процесс проектирования на 20-30\%, а так же в 3 раза сократилось время, требуемое на подготовку рабочей документации и на ее корректировку.

BIM-технологии не всегда могут математи- чески корректно описывать сооружение. Есть несколько вариантов решения этих проблем: анализирование возможного программного обеспечения, которыми владеют проектировщики; работа со строительными организациями для развития BIM для ориентации на них; выявление проблем, которые связаны с самим явлением ВІМ.

Подводя итог по анализу снижения стоимости строительного проекта можно сделать вывод о том, что несоблюдение данных принципов построения единой автоматизированной информационной системы управления стоимостью строительных проектов не избавляет от проблем таких как:

- постоянная регистрация имеющихся данных в различных системах и возможные ошибки при компиляции одной базы данных с другой, в том числе на бумажных носителях, как итог информационные разрывы, дублирование, потеря, искажение информации, увеличение затрат труда и времени;

- несоответствие информации из-за отсутствия универсальных регистров, единых справочников и методик формирования и обработки информации в разных системах;

- повышенная трудоемкость формирования информации с целью управления, потому потеря качества;

- отсутствие аналитической информации в необходимом разрезе, с нужной степенью глубины или обобщения за любой период времени;

- непрофессиональное реагирование на события хозяйственной деятельности в связи с опозданием, пониженной надежностью и непрозрачностью управления.

Результат перечисленных проблем - отсутствие информации для принятия своевременных управленческих решений и как следствие - хаос и неразбериха в делах строительных компаний, которые зачастую влекут убытки, банкротство и даже уголовные дела, что, к сожалению, наблюдается в последние годы.

После разбора данных методов снижения стоимости строительного проекта можно сделать вывод о том, что все способы упрощают и ускоряют работу со всем строительным комплексом, что увеличивает производительность. Единая автоматизированная информационная система позволит минимизировать затраты на информационное обеспечение процесса управления, оптимизировать его посредством сокращения 
времени. Использование технологий управления бюджетом в совокупности с системой производственного планирования и бухгалтерского учета обеспечивает вариативность подхода к разработке стратегий в бизнесе и управлении рисками, а так же позволяет сохранять возмож- ные варианты операции в системе планирования с итогами решения управляющего комитета организации о принятии бюджета. Применение BIM технологий позволит сократить количество возможных ошибок в проектировании и использовании материалов.

\section{Библиографический список}

1. Руководство к своду знаний по управлению проектами (Руководство РМВОК), 5-е изд. [Электронный ресурс] / Режим доступа: http://www.pm-files.com/sites/default/files/file/C/C-1/C-1-1/pmbok_5th_2013_rus.pdf / Дата обращения: 1.10 .2019

2. Shaping the Future of Construction: A Breakthrough in Mindset and Technology. Inspiring innovators redefine the industry [Электронный ресурс]/ Режим доступа: http://www3.weforum.org/docs/WEF_Shaping_the_Future_of_ Construction_full_report_.pdf/Дата обращения: 1.10.2019

3. Инфраструктурные проекты в странах Центральной и Восточной Европы и СНГ [Электронный ресурс] / Режим доступа: http://ru.investinrussia.com/data/files/sectors/ru/infra-1.pdf/ Дата обращения: 1.10.2019

4. Кравченко Т.В. ВІМ-технологии в управлении строительными проектами/ Т.В. Кравченко/ Молодой ученый. - 2019. № 3 (241). - с. 176-179. 